\title{
Regulation of Glucose Production in Newborn Infants of Diabetic Mothers
}

\author{
KATHERINE C. KING, ${ }^{(26)}$ KOU-YI TSERNG, AND SATISH C. KALHAN ${ }^{(25)}$ \\ Department of Pediatrics, Divisions of Metabolism and Neonatology, Case Western Reserve University at Cleveland \\ Metropolitan General Hospital, Cleveland, Ohio, USA
}

\begin{abstract}
Summary
The glucose homeostasis in the infants of normal and diabetic mothers was evaluated by examining the effects of exogenous glucose infusion at $4 \mathrm{mg} / \mathrm{kg} \cdot \mathrm{min}$ and quantifying the rates of glucose production and utilization. Five infants of insulin-dependent diabetic mothers (IDM), one infant of a gestationally diabetic mother and five infants of normal mothers were studied between 2-4 $\mathrm{h}$ of age. The rates of glucose production and utilization before and during glucose infusion were quantified by tracer dilution technique using $\left[6,6^{2} \mathrm{H}_{2}\right]$ glucose tracer and gas chromatographymass spectrometry. Fractional glucose uptake $\left(K_{t}\right)$ was measured at the end of infusion by administering $0.5 \mathrm{~g} / \mathrm{kg}$ glucose pulse. All diabetic women were under rigid metabolic control during pregnancy. Although basal plasma glucose levels at age $2-4 \mathrm{~h}$ were lower in the IDMs as compared with normal newborns $(43.4 \pm 3.7$ and $65.2 \pm 3.6 \mathrm{mg} / \mathrm{dl}$, mean \pm S.E., respectively), the glucose production and utilization rates were not significantly different $(3.35 \pm 0.26$ and $3.39 \pm 0.08 \mathrm{mg} / \mathrm{kg} \cdot \mathrm{min})$; therefore, the metabolic clearance rates were higher in the IDMs $(7.69 \pm 0.41 \mathrm{ml} / \mathrm{kg} \cdot \mathrm{min})$ as compared with the normal newborn infant $(5.20 \pm 0.20 \mathrm{ml} / \mathrm{kg}$ • min). Glucose infusion resulted in a greater suppression of endog. enous glucose production rate in the normal newborn infants than in the IDMs. Glucose infusion resulted in an acceleration of $K_{t}$ in the normals $(2.38 \pm 0.25 \% / \mathrm{min})$. We conclude that rigid regulation of maternal diabetes normalizes glucose production rate in IDM; however, intermittent maternal hyperglycemia may result in altered regulation of hepatic glucose production.
\end{abstract}

\section{Speculation}

Decreased suppression of systemic glucose production in response to glucose infusion observed in the infant of a diabetic mother by isotopic tracer methods may be the result of exchange of the tracer with the augmented intrahepatic substrate pools.

During adaptation to the extrauterine environment, the normal human newborn infant initiates systemic glucose production at a rate higher than that observed in the fasting adult man $(3,10,14$, 22). However, the plasma glucose concentration is maintained at a lower level than that in the adult. When maternal diabetes occurs, glucose homeostasis in the newborn is further affected by the metabolic alterations of the mother. Neonatal hypoglycemia is frequently observed and has been attributed to fetal hyperinsulinism as a consequence of maternal-fetal hyperglycemia (15). The physiologic basis for the alterations in glucose homeostasis in the infants of diabetic mothers (IDMs) has not been clearly defined. Although bolus injection of glucose showed an increased fractional rate of glucose disappearance (9), an attenuated rate of glucose uptake was observed when glucose was infused at a low rate (12). Kalhan et al. (10) first demonstrated that hypoglycemia in the IDM may, in part, be explained by the lower rate of systemic glucose production. They postulated that persistent insulin action on the liver in the presence of suppressed counter- regulatory hormonal responses could explain the attenuated glucose production rate observed in these infants.

The present study was designed to evaluate the hepatic regulation of glucose production, in infants of normal and diabetic mothers, by examining the effects of exogenous glucose infusion on systemic glucose production and utilization.

\section{MATERIALS AND METHODS}

Subjects. Five infants of insulin-dependent diabetic mothers, one infant of a gestationally diabetic mother, and five normal newborn infants were studied between $2-4 \mathrm{~h}$ of age. The insulindependent diabetic women were all of juvenile onset, Class B or $\mathrm{C}$ according to White's classification. They were admitted to the Perinatal Clinical Research Center for 3-4 wk before delivery. Rigid metabolic control was achieved during the third trimester of pregnancy by administering a mixture of neutral protamine Hagedorn insulin (NPH) and crystalline insulin twice daily with supplemental crystalline insulin as necessary. Their plasma glucose concentration ranged from $36-104 \mathrm{mg} / \mathrm{dl}$ except in subject \#2 who had marked excursions in fasting glucose. In three subjects, postprandial glucose were normal whereas two subjects (\#2 and 3) continued to have high glucose levels after meals. Diagnosis of gestational diabetes in the single patient was based on elevated postprandial plasma glucose concentrations and an abnormal oral glucose tolerance test during the third trimester of pregnancy. She was managed with diet alone. All mothers of the normal newborn infants were nonobese, had normal 2 -h postprandial glucose concentration and/or glucose tolerance test during the third trimester. Written informed consent was obtained from both parents after birth of all the infants. Maternal and umbilical plasma glucose concentrations were measured in the diabetic mothers and infants at delivery as part of the routine intrapartum care. All infants of diabetic mothers were delivered by Cesarean section (C-section). Two of the five normal newborns were delivered vaginally, whereas the other three infants were delivered by repeat $\mathrm{C}$-section. The birth weight, gestational age estimated by dates and/or Dubowitz examination, Apgar scores, and fasting glucose concentrations between age $2-4 \mathrm{~h}$ are listed in Table 1 . None of the infants received feeding or intravenous infusion of glucose before the study. Only well infants with no perinatal problems were studied.

All infants were studied in the neutral thermal environment. Two intravenous heparin "locks" with scalp vein needles or medicut catheters were placed in peripheral veins in the extremities; one for intravenous infusion and the other for sampling of venous blood. [6,6- $\left.{ }^{2} \mathrm{H}_{2}\right]-$ Glucose, 98 atom $\%\left[{ }^{2} \mathrm{H}\right]$ was purchased from Merck and Company, Inc., Dorvall, Quebec, Canada. A weighed amount was dissolved in sterile isotonic saline for intravenous infusion, sterilized by passage of the solution through a Millipore filter (size $0.22 / \mu \mathrm{m}$ ) and tested for sterility and pyrogenicity (16). After a prime injection of $5.4 \mathrm{mg} / \mathrm{kg}$ given over $15 \mathrm{~min}$, the tracer was infused at a constant rate of $60 \mu \mathrm{g} / \mathrm{kg} \cdot \mathrm{min}$ via a Holter pump for a period of $3.5 \mathrm{~h}$. Steady state deuterium enrichment of plasma glucose was achieved within $60 \mathrm{~min}$ (Fig. 1). 
Table 1. Clinical profile of infants studied

\begin{tabular}{|c|c|c|c|c|c|c|c|c|c|c|c|}
\hline \multirow[b]{2}{*}{ Infants } & \multicolumn{5}{|c|}{ Normal infants } & \multicolumn{6}{|c|}{ Infants of diabetic mothers } \\
\hline & 1 & 2 & 3 & 4 & 5 & 1 & 2 & 3 & 4 & 5 & $\begin{array}{l}\text { Infant of gestational } \\
\text { diabetic mother }\end{array}$ \\
\hline Birth weight (g) & 3140 & 2740 & 3660 & 3330 & 2920 & 3750 & 4160 & 3920 & 3600 & 2880 & 3665 \\
\hline Gestational age (wk) & 39 & 38 & 39 & 40 & 38 & 38 & 38 & 38 & 40 & 38 & 40 \\
\hline Apgar Score: $1 \mathrm{~min}-5 \mathrm{~min}$ & $8-9$ & $3-9$ & $9-9$ & $8-9$ & $9-9$ & $9-10$ & $9-10$ & $10-10$ & $9-10$ & $9-10$ & $9-9$ \\
\hline Mode of delivery & Vag $^{1}$ & $\mathrm{C} / \mathrm{S}$ & $\mathrm{C} / \mathrm{S}$ & Vag & $\mathrm{C} / \mathrm{S}$ & $\mathrm{C} / \mathrm{S}$ & $\mathrm{C} / \mathrm{S}$ & $\mathrm{C} / \mathrm{S}$ & $\mathrm{C} / \mathrm{S}$ & $\mathrm{C} / \mathrm{S}$ & $\mathrm{C} / \mathrm{S}$ \\
\hline \multicolumn{12}{|l|}{ Plasma Glucose at delivery $(\mathrm{mg} / \mathrm{dl})$} \\
\hline Maternal vein & & & & & 85 & 75 & 85 & 98 & 84 & 66 & 125 \\
\hline Umbilical vein & & & & & 83 & 47 & 76 & 91 & 63 & 56 & 100 \\
\hline Umbilical artery & & & & & 71 & 34 & 61 & 49 & 56 & 49 & 80 \\
\hline Plasma glucose at initiation of study & 68 & 54 & 65 & 58 & 77 & 40 & 43 & 43 & 44 & 30 & 62 \\
\hline Initiation of study age $(\mathrm{h}-\mathrm{min})$ & $3-50$ & $2-40$ & $3-15$ & $3-50$ & $3-10$ & $2-0$ & $3-20$ & $2-10$ & $3-20$ & $2-20$ & $2-30$ \\
\hline
\end{tabular}

${ }^{1}$ Vag., vaginal delivery.

${ }^{2} \mathrm{C} / \mathrm{S}$, cesarean section.

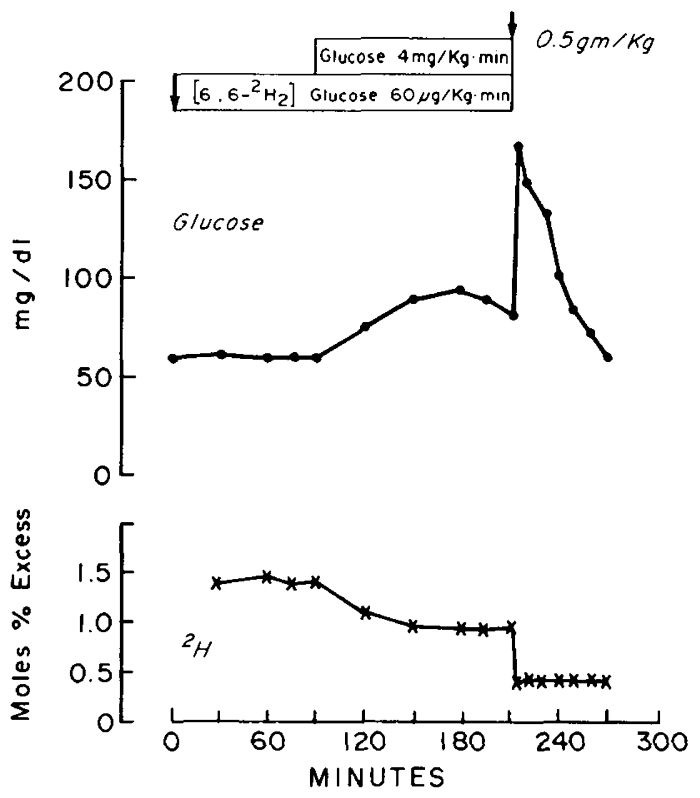

Fig. 1. Representative study of one normal newborn infant. A prime of $\left[6,6-{ }^{2} \mathrm{H}_{2}\right]$ glucose equivalent to $90 \mathrm{~min}$ of infusion, or $5.4 \mathrm{mg} / \mathrm{kg}$ was given during the first $15 \mathrm{~min}$ of $\left[6,6-{ }^{2} \mathrm{H}_{2}\right]$ glucose infusion. Steady state deuterium enrichment $\left[{ }^{2} \mathrm{H}\right]$ was achieved after $60 \mathrm{~min}$ of infusion in each period. Calculation for glucose production and glucose uptake were based on the last $30 \mathrm{~min}$ of each infusion period. Glucose disappearance rate $\left(\mathbf{K}_{\mathrm{t}}\right)$ was calculated after $0.5 \mathrm{~g} / \mathrm{kg}$ glucose pulse assuming first order kinetics.

During isotopic steady state, at $90 \mathrm{~min}$, a glucose infusion $(4 \mathrm{mg} /$ $\mathrm{kg} \cdot \mathrm{min}$ as $10 \%$ solution) was superimposed and was maintained for another $120 \mathrm{~min}$. A new steady state isotopic enrichment was established after $60 \mathrm{~min}$ of glucose infusion. The fractional disappearance rate of glucose was measured at $3.5 \mathrm{~h}$ by administering a glucose pulse $0.5 \mathrm{~g} / \mathrm{kg}$ body weight intravenously.

Heparinized blood samples were obtained at 15-30 min intervals throughout the tracer infusion and at $10 \mathrm{~min}$ intervals during the glucose pulse. Plasma was separated in the cold and kept at $-10^{\circ} \mathrm{C}$ for later analysis.

Glucose concentration of the plasma and that of the infusate were measured by the glucose oxidase method on a Beckman glucose analyzer (Beckman Instruments, Palo Alto, CA). The rate of $\left[6,6-{ }^{2} \mathrm{H}_{2}\right]$ glucose infusion was quantified from the infusate glucose concentration and the rate of infusion. The dueterium enrichment of plasma glucose was measured by combined gas chromatography-mass spectrometry using selected ion monitoring as described by Bier, et al. (2) with minor modifications. Glucose was isolated from the plasma by ion exchange chromatography. A pentaacetate derivative of glucose was prepared by mixing dry glucose with excess acetic anhydride and pyridine. M/e 100 and 98 were monitored in order to measure deuterium enrichment of plasma glucose. Standard glucose solutions of known deuterium enrichments were run everyday to calibrate for instrumental variations.

Calculations. Glucose production rate was calculated from the dilution of the infused tracer in the plasma by applying steady state kinetics. $\mathrm{Ra}=[(100 / \mathrm{Ep})-1] \times \mathrm{I}$, where $\mathrm{Ra}=$ glucose production rate $\mathrm{mg} / \mathrm{kg} \cdot \mathrm{min}, \mathrm{Ep}=$ Deuterium enrichment (moles $\%$ excess) of plasma glucose at steady state, and $\mathrm{I}=$ Rate of infusion of $\left[6,6-{ }^{2} \mathrm{H}_{2}\right]$ glucose $\mathrm{mg} / \mathrm{kg} \cdot \mathrm{min}$.

This equation assumes $100 \%\left[{ }^{2} \mathrm{H}\right]$ enrichment of infused tracer. The standard curves were prepared accordingly.

During exogenous glucose infusion, the endogenous glucose production rate was estimated by subtracting the glucose infusion rate from the isotopically measured glucose production rate.

During isotopic steady state, with unchanged plasma glucose concentration, glucose production rate $(\mathrm{Ra})$ was assumed to be equal to the rate of glucose uptake $(\mathrm{Rd})$. With changing glucose concentration: $R d=R a-V \cdot\left(G_{2}-G_{1}\right) /\left(t_{2}-t_{1}\right)$, where $V=$ volume of distribution of glucose $\mathrm{ml} / \mathrm{kg}$. This was assumed to be $400 \mathrm{ml} / \mathrm{kg}$, and $\left(\mathrm{G}_{2}-\mathrm{G}_{1}\right) /\left(\mathrm{t}_{2}-\mathrm{t}_{1}\right)$ is the rate of change in glucose concentration between times $t_{2}$ and $t_{1}$.

$$
\begin{aligned}
& \text { Metabolic clearance rate }(\mathrm{MCR}) \text { was calculated as: } \\
& \operatorname{MCR}(\mathrm{ml} / \mathrm{kg} \cdot \mathrm{min})=\frac{\mathrm{Rd}(\mathrm{mg} / \mathrm{kg} \cdot \mathrm{min})}{\text { Plasma glucose concentration }(\mathrm{mg} / \mathrm{ml})}
\end{aligned}
$$

The volume of distribution of glucose $(\mathrm{ml} / \mathrm{kg})$ was calculated from the distribution of the glucose pulse given at the end of the study by two methods; first, by extrapolating the declining plasma glucose concentration back to time zero. The increment glucose concentration was assumed to be achieved by $0.5 \mathrm{~g}$ of glucose distributed in the volume V. Second, volume of distribution was calculated by the dilution of deuterium enrichment in the plasma by the pulse. As shown in Figure 1, deuterium enrichment of glucose was in steady state before the pulse. After the glucose pulse, the deuterium enrichment decreased and achieved new steady state, suggesting complete suppression of endogenous glucose production. The decrement change of deuterium enrichment of glucose was used to calculate volume of glucose distribution.

\section{RESULTS}

Plasma glucose. The maternal and umbilical glucose concentrations in the diabetic subjects are displayed in Table 1. As shown, rigorous metabolic regulation during pregnancy resulted in normal glucose concentration at delivery. As has been shown in studies by others, a maternofetal gradient for glucose was observed in all 
subjects. The basal glucose concentration in the first $4 \mathrm{~h}$ of life was stable with minimal variance in both normal infants and in the infants of diabetic mothers (Table 2) (Period I); however, the glucose concentrations were significantly lower in the IDMs as compared with the normal newborn infants $(P<0.004)$. The plasma glucose level of the single infant of gestationally diabetic mother was $63 \mathrm{mg} / \mathrm{dl}$, a level in between the normal and the IDM. All infants were asymptomatic throughout the study period.

As a resuslt of exogenous glucose infusion at $4 \mathrm{mg} / \mathrm{kg} \cdot \mathrm{min}$, there was a rise in plasma glucose concentration in all infants (Fig. 2). As the basal glucose levels in the normal infants were higher than the IDMs, the peak glucose concentration during glucose infusion was also higher in the normals. During the second $h$ of glucose infusion however, apparently as a result of metabolic adaptation, the plasma glucose concentration declined in all normal infants, whereas a decrease in glucose levels was observed in only two infants of diabetic mothers.

Glucose production rate. As shown in Figure 1, a steady state deuterium enrichment of plasma glucose was achieved within 60 min and maintained throughout the basal period. After exogenous glucose infusion, a new steady state was achieved within $60 \mathrm{~min}$ and maintained throughout the infusion period; therefore, steady state kinetics were applied for the calculation of glucose production rates.

The mean basal glucose production rate in the normal infant was $3.4 \mathrm{mg} / \mathrm{kg} \cdot \mathrm{min}$. The rate of glucose production in the infants of diabetic mothers was not significantly different from that of the normal infants (Table 2). Exogenous glucose infusion at $4 \mathrm{mg} / \mathrm{kg}$. min resulted in suppression of endogenous glucose production in every instant although the quantitative response was variable. Suppression of endogenous glucose production was much greater in the normal infants (78\%) as compared with the IDM's (63\%).

Rate of glucose uptake and the metabolic clearance rate (MCR). During the basal state, plasma glucose concentration was unchanged in all infants. Hence, the rate of glucose uptake (Rd) was assumed to be equal to the rate of glucose appearance ( $R a)$. As the glucose levels in the IDM's were lower than the normal infants, the metabolic clearance rates were higher in the IDM's as compared with the normals. Exogenous glucose infusion resulted in an increased rate of glucose uptake in all infants and no differences were observed between the two groups. At the same time there was an increase in the MCR in all normal infants studied, but in only two of the five IDMs.

Responses to glucose pulse. The mean fractional rate of glucose disappearance in normal infants was similar to that observed in infants of diabetic mothers $(2.38 \% / \mathrm{min})$. The volume of distribution of the glucose pulse, calculated by (a) the extrapolation of glucose curve and (b) by the dilution of the isotopic tracer were similar in all infants studied. No differences were seen between infants of normal and diabetic mothers. The volume of distribution of glucose was $429 \pm 17 \mathrm{ml} / \mathrm{kg}$ (mean \pm S.E.).

\section{DISCUSSION}

The glucose homeostatic responses of the newborn of mammalian species have been shown to be at variance as compared with those observed in the adults $(4,7,8,19,20)$. When exogenous glucose is infused into a normal adult, glucose homeostasis is achieved primarily through regulation of endogenous glucose production (14). In adult humans, glucose infusion at rates less than hepatic glucose production causes a corresponding suppression of glucose production without any change in glucose uptake and a small change in plasma glucose concentration (22). These responses are the result of autoregulatory effect of glucose and due to the action of insulin on liver $(6,13,17,18)$. When the rate of exogenous glucose infusion exceeds the endogenous glucose production rate, an initial rise in plasma glucose is followed by an adaptation consisting of an increased peripheral glucose uptake and a decline in plasma glucose level to a new steady state concentration. In contrast to these responses in the adults, studies in the newborn have shown variable results depending upon the species studied, the maturity and the clinical status. Sherwood et al. (19), evaluated the responses of newborn monkey neonates to a glucose challenge of $8 \mathrm{mg} / \mathrm{kg} \cdot \min$ using tracer isotopic methods. The mature term monkey neonates and six out of eleven preterm animals developed a new steady state glucose concentration in response to a glucose challenge, conincident with a marked reduction in endogenous glucose output and a moderate increase in peripheral utilization. In contrast, studies in newborn dogs and in newborn lambs have shown a failure to suppress endogenous glucose production even after prolonged infusion of glucose at high rates $(7,20)$. Similar differences from the adult response have been suggested by a number of investigators to explain the hyperglycemic response to glucose infusion in the preterm human infant $(4,8)$. In the present study, healthy normal newborn infants were studied. As shown in the results, suppression of endogenous glucose production was observed in all infants. These observations are in contrast to those cited above and could be the result of species differences and to the fact that all infants in the present study were full term healthy infants with no evidence of stress or illness.

Responses of the IDMs. The infants of diabetic mothers showed somewhat different responses to glucose infusion as compared with the normal infant. Previous studies by us have shown an attenuated uptake of glucose infused at a low rate of $4 \mathrm{mg} / \mathrm{kg}$. min (12). In contrast, after a large glucose pulse, the fractional rate of glucose uptake has been shown to be increased in the IDMs (9). In the present study, during glucose infusion, the glucose concentration reached a plateau in four out of six infants of diabetic mothers, again suggesting an attenuated uptake or failure to adapt to an exogenous glucose load. These infants, however, did increase the rate of glucose uptake (Rd), which at steady state was similar to that observed in the normal infants. The present study further examined the regulation of hepatic glucose production in the infants of normal and diabetic mothers. The glucose infusion rate of $4 \mathrm{mg} / \mathrm{kg} \cdot \min$ was chosen because this rate is equal to the endogenous glucose production rate measured by us in previous studies using similar isotopic methods (11). Although the number of infants studied were small for statistical comparison, the data showed that the suppression of endogenous glucose production was more effective in the normal as compared with the IDM's and in both instances it was less than that in adults (14). The reasons for these differences are not clear. These could not be the result of immaturity because both the infants of normal and diabetic mothers were of similar gestation age; however, these differences could potentially represent the limitations of the tracer methods. As the concentration of glycogen and other intermediates are higher in the newborn infants, more so in the IDMs as compared with adults, the tracer will continue to be exchanged with these metabolites that are then released back into circulation as unlabeled glucose. This will suggest a continuous glucose production when measured by tracer isotopic techniques. Only simultaneous studies with tracer isotopes and transhepatic catheter will validate or refute this hypothesis.

During basal state, although the rates of glucose production were similar in the normal and IDMs in the current study, the metabolic clearance rate (MCR) was higher in the IDMs as a result of lower plasma glucose concentration. Glucose infusion for $2 \mathrm{~h}$ doubled the rate of glucose uptake ( $\mathrm{Rd})$ in both groups; however, this increase in uptake was not reflected in any corresponding change in the MCR. Verdonk et al. (21) and Cherrington et al. (5) have shown that MCR is not independent of glucose concentration and have suggested that the use of MCR to evaluate glucose utilization at differing glucose concentration is not valid. The present study and that of Best et al. (1), lend support to the thesis presented by Verdonk et al. (21) that MCR may not be used to evaluate changes in glucose utilization under conditions in which plasma glucose concentrations differ.

Previously, Kalhan et al. (10) have shown an attenuated rate of systemic glucose production in the newborn infants of diabetic 
Table 2

\begin{tabular}{|c|c|c|c|c|c|c|c|c|c|c|c|}
\hline \multirow[b]{2}{*}{ Infants } & \multicolumn{3}{|c|}{ Period I-basal state ${ }^{1}$} & \multicolumn{7}{|c|}{ Period II-glucose infusion ${ }^{2}$} & \multirow{2}{*}{$\begin{array}{c}\begin{array}{c}\text { Period } \\
\text { III-glu- } \\
\text { cose pulse }\end{array} \\
\\
\mathbf{K}_{\mathbf{t}} \\
(\% / \mathrm{min})\end{array}$} \\
\hline & $\begin{array}{l}\text { Plasma } \\
\text { glucose } \\
(\mathrm{mg} / \mathrm{dl})\end{array}$ & $\begin{array}{c}\mathrm{Ra} \\
(\mathrm{mg} / \mathrm{kg} / \\
\mathrm{min})\end{array}$ & $\begin{array}{c}\mathrm{MCR} \\
(\mathrm{ml} / \mathrm{kg} / \\
\mathrm{min})\end{array}$ & $\begin{array}{c}\text { Peak PG } \\
(\mathrm{mg} / \mathrm{dl})\end{array}$ & $\begin{array}{c}\mathrm{PG} \text { at } 120 \\
\text { min } \\
(\mathrm{mg} / \mathrm{dl})\end{array}$ & $\begin{array}{c}\text { Total Ra } \\
(\mathrm{mg} / \mathrm{kg} / \\
\mathrm{min})\end{array}$ & $\begin{array}{c}\text { Endoge- } \\
\text { nous Ra } \\
(\mathrm{mg} / \mathrm{kg} / \\
\mathrm{min})\end{array}$ & $\begin{array}{c}\% \\
\text { Suppression } \\
\text { Ra } \\
\end{array}$ & $\begin{array}{c}\mathrm{Rd} \\
(\mathrm{mg} / \mathrm{kg} / \\
\mathrm{min})\end{array}$ & $\begin{array}{c}\mathrm{MCR} \text { at } \\
120 \\
(\mathrm{ml} / \mathrm{kg} / \\
\mathrm{min})\end{array}$ & \\
\hline \multicolumn{12}{|l|}{ Normal } \\
\hline 2 & $58.5 \pm 2.0$ & 3.32 & 5.35 & 83 & 50 & 5.49 & 1.27 & 62 & 7.35 & 13.74 & 3.15 \\
\hline 3 & $61.4 \pm 2.6$ & 3.25 & 5.65 & 91 & 84 & 4.71 & 0.53 & 84 & 5.24 & 6.16 & 1.65 \\
\hline 4 & $58.6 \pm 0.5$ & 3.25 & 5.54 & 95 & 82 & 4.76 & 0.84 & 74 & 7.16 & 8.28 & 1.82 \\
\hline 5 & $72.0 \pm 2.8$ & 3.50 & 4.73 & 105 & 76 & 4.66 & 0.80 & 77 & 4.99 & 6.12 & 1.47 \\
\hline Mean \pm S.E. & $65.8 \pm 4.0$ & $3.39 \pm 0.08$ & $5.20 \pm 0.20$ & $96.6 \pm 4.7$ & $71.4 \pm 6.3$ & $4.86 \pm 0.16$ & $0.71 \pm 0.19$ & $78.6 \pm 5.6$ & $6.15 \pm 0.48$ & $8.65 \pm 1.38$ & $2.28 \pm 0.39$ \\
\hline \multicolumn{12}{|l|}{ Infants of diabetic mothers } \\
\hline 1 & $37.3 \pm 0.7$ & 2.53 & 7.11 & 56 & 49 & 4.92 & 0.92 & 64 & 5.00 & 10.26 & 3.30 \\
\hline 2 & $50.8 \pm 1.8$ & 4.01 & 7.69 & 75 & 74 & 5.76 & 1.09 & 73 & 5.76 & 7.78 & 2.23 \\
\hline 3 & $48.6 \pm 1.9$ & 3.74 & 7.46 & 106 & 96 & 5.74 & 1.32 & 65 & 5.74 & 5.98 & 2.10 \\
\hline Mean \pm S.E. & $43.5 \pm 3.7$ & $3.35 \pm 0.26$ & $7.69 \pm 0.41$ & $78.4 \pm 8.4$ & $65.2 \pm 9.1$ & $5.53 \pm 0.16$ & $1.21 \pm 0.09$ & $63.4 \pm 3.0$ & $6.27 \pm 0.75$ & $9.15 \pm 1.15$ & $2.38 \pm 0.25$ \\
\hline Infant of gestational diabetic mother: 1 & $63.0 \pm 0.5$ & 3.54 & 5.27 & 75 & 68 & 5.36 & 1.14 & 68 & 5.36 & 7.39 & 1.65 \\
\hline$P$ value normal $v s$ IDM & $<0.004$ & N.S. & $<0.01$ & N.S. & N.S. & $<0.02$ & $<0.05$ & $<0.01$ & N.S. & N.S. & N.S. \\
\hline
\end{tabular}

' Period I: prime constant infusion of $\left[6,6{ }^{2} \mathrm{H}_{2}\right]$ glucose at $60 \mu \mathrm{g} / \mathrm{kg} / \mathrm{min}$ for $90 \mathrm{~min}$.

${ }^{2}$ Period II: exogenous glucose infusion $4 \mathrm{mg} / \mathrm{kg} / \mathrm{min}$ superimposed on the $\left[6,6-{ }^{2} \mathrm{H}_{2}\right]$ glucose infusion for $120 \mathrm{~min}$.

${ }^{3}$ Period III: glucose disappearance rate $\left(\mathrm{K}_{\mathrm{t}}\right)$ after $0.5 \mathrm{~g} / \mathrm{kg}$ glucose pulse.

${ }^{4}$ Mean \pm S.E. of plasma glucose concentrations during $90 \mathrm{~min}$ basal state.

${ }^{5} \mathrm{PG}$ : plasma glucose 


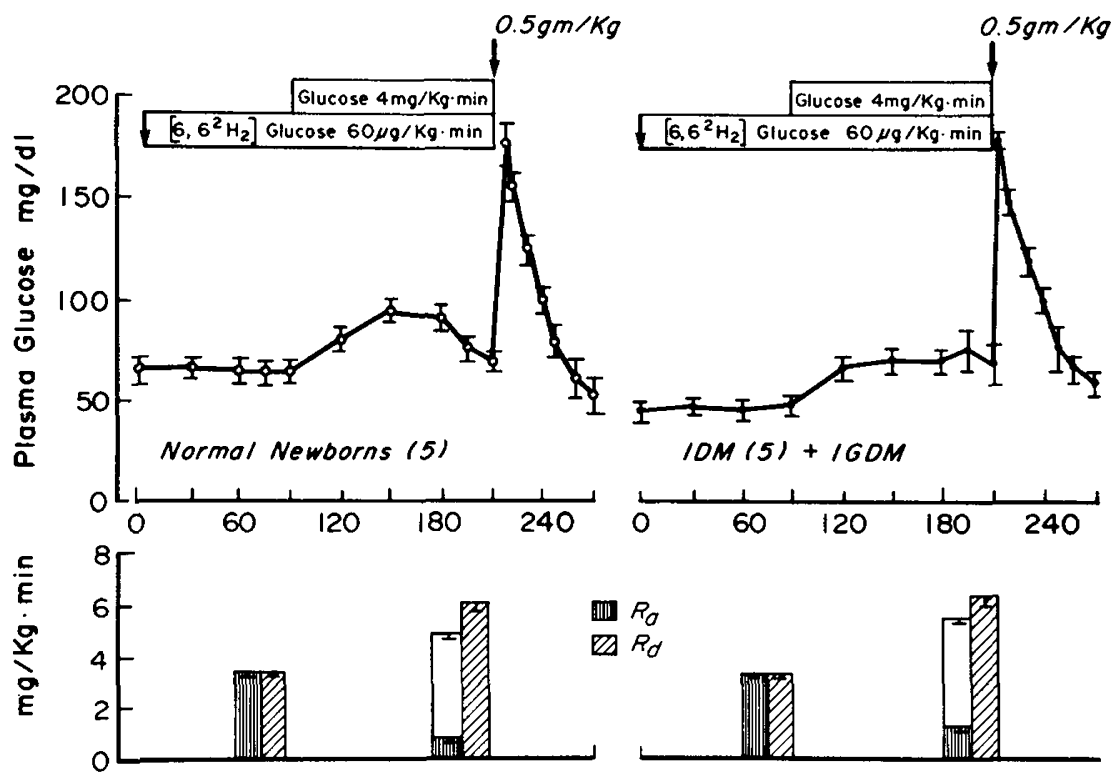

Fig. 2. Plasma glucose concentrations of normal newborn infants (left panel) and infants of diabetic mothers (right) during the study periods. Glucose production $\mathbb{U}$ and glucose uptake $\mathbb{Q}$ were calculated during the last $30 \mathrm{~min}$ of each infusion period. $\square$ represents the exogenous glucose infusion rate. All data are experessed as mean \pm S.E.

mothers. In the present study, these differences were not observed. This change may reflect the improved antenatal management of diabetic pregnancy. In spite of rigorous antepartum management, however, two IDM's were large-for-gestational age and all of them had lower basal glucose concentration as compared with the noraml newborn infants.

\section{REFERENCES AND NOTES}

1. Best, J. D., Taborsky, G. J., Holter, J. B., and Porte, D.: Glucose disposal is not proportional to plasma glucose level in man. Diabetes, 30: 847 (1981).

2. Bier, D. M., Arnold, K. J., Sherman, W. R., Holland, W. H., Holmes, W. F., and Kipnis. D. M.: In vivo measurement of glucose and alanine metabolism with stable isotopic tracers. Diabetes, 26: 1005 (1977).

3. Bier, D. M., Leake, R. D., Haymond, M. W., Arnold, K.-J., Gruneke, L. D., Sperling, M. A., and Kipnis, D. M.: Measurement of "true" glucose production rates in infancy and childhood with 6,6-dideuteroglucose. Diabetes, 26: 1016 (1977).

4. Burstein, R. L., Papile, L. A., and Greenberg, R. E.: Mechanisms of hyperglycemia in small premature infants. Pediatr. Res., 14: 568 (1980).

5. Cherrington, A. D., Williams, P. E., and Harris, M. S.: Relationship between the plasma glucose level and glucose uptake in the conscious dog. Metabolism, 27: 787 (1978).

6. Cherrington, A. D., Chiasson, J. L., Liljenquist, J. E., Jennings, A. S., Keller, U., and Lacy, W. W.: The role of insulin and glucagon in the regulation of basal glucose production in the postabsorptive dog. J. Clin. Invest., 58: 1407 (1976).

7. Cowett, R. M., Susa, J. B., Oh, W., and Schwartz, R.: Endogenous glucose production during constant glucose infusion in the newborn lamb. Pediatr. Res., 12: 853 (1978).

8. Cowett, R. M., Oh, W., Pollak, A., Schwartz, R., and Stonestreet, B. S.: Glucose disposal of low birth weight infants: Steady state hyperglycemia produced by constant intravenous glucose infusion. Pediatrics, 63: 389 (1979).

9. Isles, T. E., Dickson, M., and Farquhar, J. W.: Glucose tolerance plasma insulin in newborn infants of normal and diabetic mothers. Pediatr. Res., 2: 198 (1968).

10. Kalhan, S. C., Savin, S. M., and Adam, P. A. J.: Attenuated glucose production rate in newborn infants of insulin dependent diabetic mothers. N. Engl. J. Med., 296: 375 (1977).

11. Kalhan, S. C., Bier, D. M., Savin, S. M., and Adam, P. A. J.: Estimation of glucose turnover and $\left[{ }^{1:} \mathrm{C}\right]$ recycling in the human newborn by simultaneous $\left[{ }^{13} \mathrm{C}\right]$ glucose and $\left[6,6{ }^{2} \mathrm{H}_{2}\right]$ glucose tracers. J. Clin. Endocrinol. Metab., 50: 456 (1980).
12. King, K. C., Adam, P. A. J., Clemente, G. A., and Schwartz, R.: Infants of diabetic mothers: attenuated glucose uptake without hyperinsulinemia during continuous glucose infusion. Pediatrics, 44: 381 (1969).

13. Liljenquist, J. E., Mueller, G. L., Cherrington, A. D., Perry, J. M., and Rabinowitz, D.: Hyperglycemia per se (insulin and glucagon withdrawn) can inhibit hepatic glucose production in man. J. Clin. Endocrinol. Metab., 48: 171 (1979).

14. Long, C. L., Spencer, J. L., Kinney, J. M., and Geiger, J. W.: Carbohydrate metabolism in normal man and effect of glucose infusion. J. Appl. Physiol., 31: 102 (1971).

15. Pederson, J., Bojsen-Moller, B., and Poulsen, H.: Blood sugar in newborn infants of diabetic mothers. Acta Endocrinol., 15: 33 (1954).

16. Pyrogen test, The United States Pharmacopeia, Seventeenth Revision. New York, U.S.P., 1965, p. 863.

17. Sacca, L., Hendler, R., and Sherwin, R. S.: Hyperglycemia inhibits glucose production in man independent of changes in glucoregulatory hormones. $J$. Clin. Endocrinol. Metab., 47: I160 (1978).

18. Sacca, L., Vitale, D., Cicala, M., Trimarco, B., and Ungaro, B.: The glucoregulatory response to intravenous glucose infusion in normal man; roles of insulin and glucose. Metabolism, 30: 457 (1981).

19. Sherwood, W. G. Hill, D. E., and Chance, G. W.: Glucose homeostasia in preterm rhesus monkey neonates. Pediatr. Res., 11: 874 (1977).

20. Varma, S., Nickerson, H., Cowan, J. S., and Hetenyi, Jr., G.: Homeostasic responses to glucose loading in newborn and young dogs. Metabolism, 22: 1367 (1973).

21. Verdonk, C. A., Rizza, R. A ., and Gerich, J. E.: Effects of plasma glucose concentration on glucose utilization and glucose clearance in normal man. Diabetes, 30: 535 (1981).

22. Wolfe, R. R., Allsop, J. R., and Burke, J. F.: Glucose metabolism in man: responses to intravenous glucose infusion. Metabolism, 28: 210 (1979).

23. This work was published in part as abstracts in Pediatr. Res., 14: 576 (1980) and Diabetes, 30: I34A (1981).

24. This work was supported by grants HD 11089 and RR 00120 from the National Institute of Child Health and Human Development.

25. Satish C. Kalhan is recipient of a Research Career Development Award - K04 Am 00801 from the National Institutes of Health.

26. Requests for reprints should be addressed to: Katherine C. King, M.D., Department of Pediatrics, Cleveland Metropolitan General Hospital, 3395 Scranton Road, Cleveland, OH 44109.

27. The authors thank Pam Dreher and Margaret Chou for their expert technical help and Sandee Riedrich for secretarial assistance.

28. Received for publication August 19, 1981.

29. Accepted for publication February 5, 1982 